\title{
COCONUT DISEASES
}

The Diseases of the Coconut Palm

By Prof. H. R. Briton-Jones. Revised by Prof. Ernest Entwistle Cheesman. Pp. xvi $+176+37$ plates. (London: Baillière, Tindall and Cox, 1940.) 10s. $6 d$.

70 those who worked in close contact with the late Prof. H. R. Briton-Jones, professor of mycology in the Imperial College of Tropical Agriculture, Trinidad, the keen interest which he invariably displayed in attempting to make scientific investigations of direct use to the planter, and his sympathy towards the practical and economic difficulties by which the tropical agriculturist is so frequently beset, are common knowledge. This attitude is implicit in the work now under review. Its object, clearly stated in the preface, is ". . . to give those growers who have not had the advantage of a scientific training, and those agricultural officers who, through pressure of work in other directions or lack of library facilities, are unable to keep up with modern seientific literature, an account of the diseases of the tall coconut palm in simple English, with, it is hoped, a sympathetic understanding of the practicable limits of labour intelligence and the monetary unit in crop production under tropical conditions". On this basis the book must be judged. It may be said at once that in respect of directness and simplicity of presentation and choice of illustration the author has succeeded in no small measure.

The approach is appropriate to the subject. The tall coconut palm, one of the major tropical crops, is widespread in its distribution. Its cultivation has been attempted over a wide range of conditions, often unfavourable, with concomitant disease incidence and financial loss. Not least, the size and nature of the plant render it one of the least suitable subjects for the study of physiological processes. Where these are related to pathological aspects the approach tends to be by inference and analogy rather than by direct experimental observation. The author of the present work has faced such difficulties courageously, and, at the risk of laying himself open to criticism, has not hesitated to speculate freely on occasions where precise information has been scanty. The same attitude applies to the criticisms which are here and there made of the findings of other investigators.

The opening chapter refers to the bud rot complex, the analysis submitted doing much to clear the way for a straightforward exposition of the diseases described in subsequent chapters. The term 'bud rot', in fact, with one exception
(Phytophthora palmivora), "is merely descriptive of a concomitant symptom of different kinds of diseases fatal to the coconut palm". Thereafter bronze leaf wilt, Phytophthora bud rot, tapering stem wilt, red ring disease, false wilt and lightning strike, stem-bleeding disease, root and leaf diseases, gumming disease and dropping of nuts, are dealt with in considerable detail, symptoms, environmental conditions, and relevant cultural practices being clearly indicated.

The account of bronze leaf wilt, attributed to drought in conjunction with unfavourable soil factors, is typical of difficulties arising in the study of this crop. In some instances the line between health and disease is very narrow ; some affected plants may recover whereas others, in what appears to be approximately the same pathological condition, may succumb rapidly. Close and continuous observation is necessary in order that the slightly different symptoms may be correctly assessed. In a malady where anatomical investigation yields almost no symptoms of definite diagnostic value, such behaviour as that cited indicates clearly the difficulties and pitfalls that await the pathologist. Again, roots, though frequently abnormal and in a decayed condition, so far have only yielded a Diplodia species, an organism regarded as being only of secondary importance. Nevertheless, bronze leaf wilt ranks very definitely as a destructive disease, and, as the author's photographs and text plainly show, is one that may take a heary toll of plantations of all ages. The account of this disease also directs attention to the fate that inevitably overtakes a crop the cultivation of which has been attempted under unfavourable environmental conditions.

The discussion of the several major diseases is on the same broad basis as that indicated for bronze leaf wilt. Where the author does not agree with the findings of other workers he has not hesitated to say so. In several such instances it is only too evident that our information regarding the physiological processes and reactions of such an unwieldy object as the coconut is quite inadequate, and that theory rather than fact will to some extent tend to hold the field until this defect is made good.

Lastly, in recommending this very readable book to planter and pathologist, reference should be made to the careful revision carried out by Prof. E. E. Cheesman and to the useful additions of recent literature incorporated by him, which bring the book quite up to date.

C. W. WARDLAW. 